\title{
A temporal perspective on emotions
}

Citation for published version (APA):

Nübold, A., Kuppens, P., \& Verduyn, P. (2020). A temporal perspective on emotions. In Y. Griep, \& S. D. Hansen (Eds.), Handbook on the Temporal Dynamics of Organizational Behavior (1 ed., pp. 221-236). Edward Elgar Publishing. Research Handbooks in Business and Management series https://doi.org/10.4337/9781788974387.00023

Document status and date:

Published: 01/01/2020

DOI:

10.4337/9781788974387.00023

Document Version:

Publisher's PDF, also known as Version of record

\section{Document license:}

Taverne

\section{Please check the document version of this publication:}

- A submitted manuscript is the version of the article upon submission and before peer-review. There can be important differences between the submitted version and the official published version of record.

People interested in the research are advised to contact the author for the final version of the publication, or visit the DOI to the publisher's website.

- The final author version and the galley proof are versions of the publication after peer review.

- The final published version features the final layout of the paper including the volume, issue and page numbers.

Link to publication

\footnotetext{
General rights rights.

- You may freely distribute the URL identifying the publication in the public portal. please follow below link for the End User Agreement:

www.umlib.nl/taverne-license

Take down policy

If you believe that this document breaches copyright please contact us at:

repository@maastrichtuniversity.nl

providing details and we will investigate your claim.
}

Copyright and moral rights for the publications made accessible in the public portal are retained by the authors and/or other copyright owners and it is a condition of accessing publications that users recognise and abide by the legal requirements associated with these

- Users may download and print one copy of any publication from the public portal for the purpose of private study or research.

- You may not further distribute the material or use it for any profit-making activity or commercial gain

If the publication is distributed under the terms of Article $25 \mathrm{fa}$ of the Dutch Copyright Act, indicated by the "Taverne" license above, 


\section{A temporal perspective on emotions Annika Nübold, Peter Kuppens, and Philippe Verduyn}

Emotions are truly ubiquitous phenomena. As they are ultimately tied to human nature, no single day passes without them. Logically, also for humans at work, emotions are omnipresent. They sit with us in team meetings and performance appraisals, influence management decisions and service interactions, impact our creativity and performance, and spice up our race to meet deadlines (Barsade \& Gibson, 2007). Since the start of the "affective revolution" 40 years ago, practitioners and scientists have come to acknowledge the central role of emotions for understanding and managing organizational behavior (OB; Barsade, Brief, \& Spataro, 2003). In the course of that, employees' emotions have been linked to a variety of work outcomes, further underlining their importance for organizations (for overviews see e.g., Ashkanasy \& Humphrey, 2011; Barsade \& Gibson, 2007; Elfenbein, 2007).

Although the dramatic increase of scholarly interest in feelings at work has led to an extensive amount of literature (Ashkanasy \& Humphrey, 2011; Barsade \& Gibson, 2007; Elfenbein, 2007), there is still much to discover. This becomes particularly clear when peeking at more fundamental psychological disciplines, which were naturally more able and inclined to invest their time into advancing their understanding of the temporal nature and dynamic unfolding of emotions. Several scholars (Barsade et al., 2003; Brief \& Weiss, 2002) noted already over a decade ago that it was time for organizational behavior to take note of advances that had been made in other domains. As will become apparent in this chapter, although organizational scholars have accumulated an excellent body of research on workplace antecedents, processes, and outcomes of emotions at work, this literature is still characterized by a surprisingly large number of cross-sectional (i.e., non-temporal) designs and analyses, incongruent with the conceptualization of emotions as an inherently dynamic construct. A stronger application of a temporal perspective on emotions is not only important for conceptual clarity and construct validity, but is also meaningful for practical reasons. Fundamental research showing that disturbances in emotion dynamics are characteristic for a wide range of mental disorders (Wichers, Wigman, \& Myin-Germeys, 2015) and psychological strain reactions, such as burnout (Maslach, Schaufeli, \& Leiter, 2001), could directly benefit employees in organizations.

The aim of the present chapter is, thus, to build a bridge between organizational and fundamental emotion research and lay the ground for more research on the temporal characteristics of feelings at work. In the first section of this chapter, we will introduce emotions as an inherently dynamic construct and briefly discuss the historical development of its conceptualization. In the second section, we will review and critically reflect on the current body of organizational emotion research with regard to its temporal character. In the third section, we will describe a general theoretical framework on emotion dynamics derived from fundamental emotion research, discussing the principles underlying emotion dynamics and associated features of emotion unfolding. In the final section of this chapter, we will present examples of how scholars could apply (parts of) the described 
framework to organizational phenomena in order to advance our temporal understanding of emotions at work.

\section{HOW DYNAMIC ARE CONCEPTUALIZATIONS OF EMOTIONS? A BRIEF HISTORICAL REVIEW}

As emotions naturally change across time, a full theoretical understanding of them can only be reached when their dynamic properties are examined (Frijda, 2007). In organizational behavior, a variety of definitions of emotions have emerged over the years, containing motivational, physiological, psychological, cognitive, and behavioral components (for an overview, see Ashkanasy, 2003) and acknowledging the temporal nature of emotions to varying degrees. Organizational scholars usually agree on definitions stating that emotions are elicited by a particular stimulus or cause and are relatively intense and short-lived (Frijda, 1986). Moods, in comparison, are consensually perceived as lasting longer and being more diffuse and less dependent on a specific target (Frijda, 1986).

Although nowadays naturally used in definitions, the qualification of emotions as "relatively short-lived" has taken the scientific community quite some time (Verduyn, Delaveau, Rotgé, Fossati, \& Van Mechelen, 2015) and may still be the subject of debate today. For a long time, scholars assumed that emotions are very brief phenomena that only last for seconds or a couple of minutes at most (Ekman, 1984). According to this perspective, emotions operate like a lightbulb switching on when a survival-relevant stimulus is encountered (e.g., seeing a lion), staying on as long as the stimulus is present (e.g., running while being chased by the lion), and turning off when the stimulus is removed from sight (e.g., having escaped from the lion). While such dynamic patterns may accurately reflect the emotional life of (certain classes of) animals, human emotions do not typically end when the emotion-eliciting stimulus is no longer physically present (Rimé, 2009).

Nowadays, it is widely acknowledged that emotions may be shorter relative to moods, but must not be short in an absolute sense. Contrasting with the traditional conviction that emotions are activity bursts of brief duration, several studies conducted during the nineties revealed that emotions typically last for minutes, hours, or even longer (Frijda, Mesquita, Sonnemans, \& Van Goozen, 1991; Gilboa \& Revelle, 1994; Scherer \& Wallbott, 1994). These findings led to the realization that research on emotions, including organizational behavior research, had only focused on a very small fraction of the emotional response (i.e., the onset), and several leading scholars made calls to put the topic of emotion dynamics on top of the research agenda (Davidson, 1998; Scherer, 2000). Although today all leading general emotion theories - including basic emotion theories (Tracy, 2014), appraisal theories (Moors, 2014), and constructionist theories (Barrett, 2014) - agree that emotions are inherently dynamic processes that unfold over time, and empirical studies on the antecedents and consequences of patterns of emotion unfolding are currently rapidly accumulating (Kuppens \& Verduyn, 2017), the organizational literature has still to catch up with the recent insights gained in this area. In the following, we will review and critically reflect upon the temporal character of the organizational body of research on emotions in the workplace. 


\section{HOW DYNAMIC IS OB'S RESEARCH ON EMOTIONS AT WORK? A CRITICAL REFLECTION}

Organizational research on emotions has resulted in a rather heterogeneous body of literature spanning a wide range of (often only loosely connected) topics and themes (Elfenbein, 2007). In the last years, several scholars have tried to better structure this body of research by introducing generic models or frameworks that look at emotions from different organizational levels or process stages (Ashkanasy, 2003; Elfenbein, 2007). As the aim of this chapter is to critically reflect on the temporal nature of organizational emotions research, we will subsequently merely focus on phenomena that, by definition, have the potential to be investigated in a temporal way. Furthermore, as a complete review of emotional phenomena in organizations is beyond the scope of this chapter, we will focus on two broad areas of research - the experience and expression of emotion - that have emerged as popular themes in the past decades.

\section{Emotional Experience}

Affective experiences in the workplace have, since its introduction, most often been studied in relation to Affective Events Theory (AET; Weiss \& Cropanzano, 1996). Highlighting the central role of affect (i.e., emotion and mood) for employees' attitudes and behavior, Weiss and Cropanzano introduced AET as a response to cognitively oriented models of job satisfaction. AET represents a 'macrostructure' for understanding affect at work (Weiss \& Beal, 2005) and proposes that employees experience a number of workplace events that have the power to elicit certain affective responses, which, in turn, influence their subsequent job attitudes and work behavior.

Organizational scholars have used the AET framework to identify an impressive variety of antecedents (e.g., stressful events, social interactions, and organizational rewards and punishments; Brief \& Weiss, 2002; Elfenbein, 2007) and/or consequences of employees' affect at work (e.g., job satisfaction, performance, and counterproductive work behavior; Ayoko, Callan, \& Härtel, 2003; Brown, Westbrook, \& Challagalla, 2005; Ilies \& Judge, 2002; Rothbard \& Wilk, 2011). This research has generally rather focused on more generic and diffuse affective responses of employees to workplace events (i.e., moods), often utilizing measures of positive and negative affect (e.g., feeling excited, enthusiastic, active, or distressed, upset, nervous) as measured in the Positive and Negative Affect Schedule (PANAS) by Watson, Clark, and Tellegen (1988). Furthermore, this research has largely emphasized reactions to negative events, mostly in the context of stress and occupational health research (Brief \& Weiss, 2002; Elfenbein, 2007; Weiss \& Beal, 2005).

Organizational research on distinct emotions has generally been much scarcer (Brief \& Weiss, 2002; Gooty, Gavin, \& Ashkanasy, 2009), despite large-scale qualitative studies that have identified a wide variety of discrete emotions in organizations (e.g., pride, relief, excitement, disappointment, anger, embarrassment, regret; Basch \& Fisher, 2000) and explicit calls for more research on discrete emotions within the AET framework (Weiss \& Beal, 2005). In the last years, a number of quantitative studies have shown that organizational injustice (e.g., Barclay, Skarlicki, \& Pugh, 2005) as well as workplace conflict (Rispens \& Demerouti, 2016) are related to a number of discrete negative emotions (e.g., guilt, sadness, shame, anger and hostility) and, in turn, predict daily in-role 
and extra-role performance (Rispens \& Demerouti, 2016). Furthermore, a recent metaanalysis (Shockley, Ispas, Rossi, \& Levine, 2012) has evidenced negative links between sadness and task performance, anger and organizational citizenship behavior (OCB), and positive links between a variety of discrete negative emotions (i.e., anxiety, frustration, anger, sadness, hostility, envy, and guilt) and counterproductive work behavior. In contrast, happiness had a rather strong relationship with task performance, while a number of distinct emotions (i.e., joy, pride, attentiveness, contentment, and affection) were positively related to OCB. Notably, most of the studies included in the meta-analyses were cross-sectional and correlational in nature.

As Weiss and Beal $(2005$, p. 7) state, AET "was intended to encourage organizational researchers to pay closer attention to the way work is experienced, the way time is psychologically structured, the way life naturally ebbs and flows at work." Many researchers have followed Weiss and Cropanzano's (1996) call for within-person research on fluctuations in emotional states and have emphasized how conclusions on the intra-individual level may differ from those on the between-person level (e.g., regarding the relation between positive affect and performance; Fisher, 2003). However, a lot of studies in the field of organizational emotion research still fail to appropriately model processes and to incorporate time on a conceptual and methodological level, for example by focusing on the onset, duration, and dynamics (i.e., the change patterns) of emotional phenomena (Gooty et al., 2009; Roe, 2008). As emphasized by Weiss and Cropanzano, emotions follow an episodic structure, and affect researchers should take the dynamic and temporal nature of emotions seriously.

Notably, a few exceptions exist and a number of studies drawing on AET have focused on the dynamic features of emotions at work, such as their temporal patterns. For example, applying an "affective shift model", Bledow and colleagues (Bledow, Rosing, \& Frese, 2013; Bledow, Schmitt, Frese, \& Kühnel, 2011) focused on the dynamic interplay of positive and negative affect (i.e., mood and emotions), showing that negative affective states in the morning, followed by positive affect during the day, was particularly adaptive and positively related to employees' work engagement and creativity. Furthermore, a study by Yang, Simon, Wang, and Zheng (2016) illustrated that different patterns of affective changes across a working day were differentially related to different forms of employee performance on the following day. While within-person increases of positive affect accompanied by decreases in negative affect predicted employees' organizational citizenship behavior on the following day, increases of positive affect accompanied by increases in negative affect predicted task performance on the following day. The results of these studies illustrate that the consideration of affective sequences and parallel patterns provides valuable new insights for the prediction of important work behaviors.

\section{Emotional Expression}

While affective events theory focuses on the experience of emotional states, research on emotional labor and emotion regulation at work focuses on the interplay of emotional demands and emotional expression. Paradoxically, the actual experience of emotion is often not included in emotional labor research (Grandey \& Gabriel, 2015). According to the emotional labor literature, emotion regulation is defined as a dynamic process that varies within individuals and evolves as a reaction to a mismatch between felt and required 
emotions during employee-customer interactions (Hülsheger \& Schewe, 2011). Research on emotional labor usually differentiates two (and lately three) different strategies of emotional regulation (e.g., Gross, 1998; Martínez-Iñigo, Totterdell, Alcover, \& Holman, 2007). Whereas surface acting describes the display of emotions that are incongruent to what the actor is really feeling, deep acting refers to the attempt to truly experience, and consequently display, the emotions the actor is supposed to display. For example, a steward who has to deal with an angry customer engages in surface acting when he feels frustrated and angry, but still provides the required "service with a smile" in order to comply with company policies. In contrast, a waitress who engages in deep acting would try to modify her feelings of anger by using cognitive strategies (e.g., taking the client's perspective) aiming to genuinely show concern. Recently, these two strategies have been supplemented by a third form of emotion regulation, namely automatic regulation (e.g., Martínez-Iñigo et al., 2007). Like deep acting, automatic regulation is an antecedentfocused form of emotion regulation and describes the spontaneous authentic experience and display of desired emotional states (Martínez-Iñigo et al., 2007). For example, a receptionist who is faced with an angry customer whose booking was accidentally canceled may also spontaneously empathize with that person and authentically show compassion, a reaction that would be in line with his job demands. In the emotional labor literature, automatic regulation is still regarded as an emotion regulation strategy as it is assumed that regulation may also occur in a non-deliberate, effortless way.

Several meta-analyses have recently demonstrated the significance of emotional labor research (Hülsheger \& Schewe, 2011; Kammeyer-Mueller et al., 2013; Mesmer-Magnus, DeChurch, \& Wax, 2012). For example, drawing on a sample of 95 independent studies, the meta-analysis by Hülsheger and Schewe has shown that surface acting is moderately related to impaired well-being and job dissatisfaction while showing a relatively weak negative relationship with performance outcomes. In contrast, deep acting was found to have only mild costs for employees, showing weak relations with impaired well-being and job attitudes, and to be effective in terms of customer reactions (i.e., positive relationships with emotional performance and customer satisfaction). Importantly, all meta-analyses were conducted on the between-person level, representing the tendency of prior research to focus on individual differences in emotion regulation strategies, despite their dynamic nature (Grandey \& Gabriel, 2015; Grandey \& Melloy, 2017; Grandey \& Sayre, 2019).

In the field of emotional labor, this mismatch in concept and measurement has been criticized (Gabriel \& Diefendorff, 2015; Grandey \& Gabriel, 2015). Thus, scholars have called for more momentary assessments and analyses on the within-person level in order to fully capture the dynamics of the emotional experience and emotion regulation at work (Gabriel \& Diefendorff, 2015; Grandey \& Gabriel, 2015; Grandey \& Melloy, 2017; Grandey \& Sayre, 2019). Studies using an experience sampling methodology have markedly increased during the last decade, recognizing the transient and dynamic nature of emotions. These studies have evidenced that about 30-40 percent of variation in emotion regulation strategies, such as deep acting, is on the within-person level (Judge, Woolf Fluegge, \& Hurst, 2009; Schreurs, Guenter, Hülsheger, \& van Emmerik, 2014; Scott \& Barnes, 2011). Furthermore, those studies have shown that within-person experiences of emotion regulation were preceded (Trougakos, Beal, Green, \& Weiss, 2008) as well as followed by positive or negative affect (Judge et al., 2009; Scott \& Barnes, 2011) and were related to important work outcomes, such as daily job satisfaction, work engagement, 
performance, and withdrawal (Chi \& Grandey, 2019; Chi, Grandey, Diamond, \& Royer Krimmel, 2011; Diestel, Rivkin, \& Schmidt, 2015; Hülsheger, Lang, Schewe, \& Zijlstra, 2015; Judge et al., 2009; Schreurs et al., 2014; Scott \& Barnes, 2011).

However, the temporal process of emotion regulation as suggested by Gross (1998) - assuming a sequential order of an event, the modification of felt emotions (i.e., deep acting), experience of emotions, and modification of the behavioral expression of the emotions (i.e., surface acting) - has still not been distinguished in current studies (Grandey \& Melloy, 2017). As noted by Gabriel and Diefendorff (2015, p. 1804), "despite dynamic theory on the topic, empirical tests have largely ignored within-episode variability in emotional labor, relying on assessments of emotional labor focused on the person, day, or interaction level of analysis." As an exception, Gabriel and Diefendorff have applied a dynamic within-person approach to emotional labor using continuous momentary assessments in a lab study, thereby explicitly incorporating time on a conceptual and methodological level. In an aim to tease apart the emotional labor process as it unfolds during a performance episode, participants were asked to provide continuous ratings of their felt emotions as well as deep acting and surface acting while listening to the recording of a difficult interaction they had experienced in a call to a customer (confederate) during a simulation. Using real-time momentary self-report measures, every 200 milliseconds participants provided ratings of how they felt via mouse movements along a 20-point scale. Results revealed that emotions and emotion regulation strategies changed continuously as a causal result of customer behavior and were linked over time. Surprisingly, surface acting and deep acting were used simultaneously to manage emotional labor demands, a finding that is incongruent to the assumptions of the emotion regulation model by Gross (1998).

As another exception, emotional labor research on "affect spin" has incorporated temporal dynamics on a conceptual level. Affect spin is defined as an individual difference variable referring to the variability of an individual's affective states over time (Kuppens, Van Mechelen, Nezlek, Dossche, \& Timmermans, 2007). Typically, affect spin is assessed with the help of experience sampling methodology and provides a measure of an individual's general reactivity to affective events (Beal \& Ghandour, 2011). For example, a study by Beal, Trougakos, Weiss, and Dalal (2013) with a sample of restaurant servers found that individuals high in affect spin experienced more strain as a result of surface acting and were more depleted by the act of emotion regulation. The authors also found, however, that affect spin also worked as a buffer, and that the effects of experienced strain on fatigue were higher for those participants low in affect spin.

\section{Conclusion}

Departing from a focus on stable individual differences, OB scholars focusing on emotions at work have already started to redirect their attention to the intra-individual level of analysis by making use of experience sampling methodology (e.g., diary studies), thus accounting for fluctuations in emotions, their triggers, and outcomes (Brief \& Weiss, 2002). However, these within-person relationships have often been analyzed in a crosssectional fashion (e.g., in terms of daily relationships), making conclusions about temporal processes and causality impossible (Brief \& Weiss, 2002; Grandey \& Gabriel, 2015). For example, daily positive affect has been linked with daily feelings of competence and 
autonomy (Sheldon, Ryan, \& Reis, 1996) or daily job satisfaction (Ilies \& Judge, 2002), and daily emotional labor has been linked with daily work engagement, performance, and counterproductive behavior (Chi \& Grandey, 2019; Schreurs et al., 2014; Scott \& Barnes, 2011). Although the examination of within-person emotional experiences and their correlates has its merits, the amount of "temporalness" represented in such analyses is still limited. Increasingly, scholars are designing studies where emotions and emotional processes, such as emotion regulation, are measured in the field at separate points in time, allowing analyzing lagged effects and implying a temporal sequence (Demerouti \& Cropanzano, 2017; Hülsheger et al., 2015; Ouweneel, Le Blanc, Schaufeli, \& van Wijhe, 2012; Wagner, Barnes, \& Scott, 2014). Nonetheless, organizational scholars should aim to go beyond the analysis of within-person variation of emotional experiences and make further use of sophisticated designs and analyses. Much can still be learned from investigating the temporal characteristics of emotion dynamics in organizational behavior (for exceptions see e.g., Bledow et al., 2011; Gabriel \& Diefendorff, 2015).

\section{HOW IS TIME REPRESENTED IN FUNDAMENTAL RESEARCH ON EMOTIONS? A CLOSER LOOK AT PRINCIPLES AND FEATURES}

In the last years, a large number of fundamental emotion researchers contributed to the development of a research field focusing on emotion dynamics. Formally, the study of emotion dynamics involves "the study of ... the trajectories, patterns, and regularities with which emotions, or one or more of their subcomponents (such as experiential, physiological, or behavioral components) fluctuate across time, their underlying processes, and downstream consequences" (Kuppens \& Verduyn, 2015. p. 72). Research on emotion dynamics encompasses both studies on temporal changes occurring during emotional episodes and during affect trajectories. An emotional episode refers to a period of emotion unfolding, starting with the occurrence of an emotion-eliciting event and ending with emotion intensity returning to its baseline level (for a discussion of the end of an emotional episode, see Van Mechelen, Verduyn, \& Brans, 2013). Affect trajectories refer to the continuous flow of emotions, with dynamics in these trajectories encompassing both emotional episodes and mood changes. The difference between emotional episodes and affect trajectories can perhaps be best understood by the following metaphor: examining affect trajectories corresponds to studying the flow of a river, while examining emotional episodes corresponds to examining what happens when a stone is thrown in the river (Koval, 2014).

\section{Principles of Emotion Dynamics}

Four principles have been proposed to underlie changes in emotional episodes and affect trajectories over time. In this section we will briefly describe these principles (for a more detailed treatment, see Kuppens \& Verduyn, 2017). The first is called the principle of contingency: emotions consist of responses to events that are extrinsic to the emotional response. This principle reflects the key functionality of emotions, namely to alert us to the occurrence of changes in our environment that have relevance for our concerns, 
as well as to prepare our body and mind for action (Frijda, 2007; Scherer, 2009). These events are extrinsic to the emotional response but can be external (e.g., losing one's job) or internal (e.g., recalling having lost one's job) to the person experiencing them. Changes in the nature of these events over time or the occurrence of new events impact the unfolding of the associated emotional response (Barrett, 2014; Moors, 2014). For example, an argument with a colleague may initially elicit an intense feeling of anger. However, this emotion will become weaker or disappear altogether when the colleague apologizes (i.e., change of the nature of the original event) or when receiving news about a job promotion (i.e., a new event overwriting the effect of the original event).

The second and third principles refer to two (usually) opposing forces impacting emotion unfolding that are situated within the emotion itself. On the one hand, emotional states are intrinsically resistant to change, resulting in a general tendency to carry over from one moment to the next - the principle of inertia. This tendency of emotions to reinforce themselves results from the fact that people appraise novel stimuli in a moodcongruent way such that neutral or even positive events are typically perceived in a negative manner when experiencing a negative emotion (LaBar \& Cabeza, 2006; Lerner $\&$ Keltner, 2001; Yiend, 2010). This force may be so strong that it overwrites the effect of counteracting extrinsic events. For example, when experiencing intense sadness due to job loss, activities that once elicited positive emotions may no longer be experienced as pleasant, and may (temporarily) not help us recover from the negative event.

On the other hand, the principle of regulation states that emotions are continuously regulated towards a desired emotional state. In most cases emotion regulation goals are aimed at down-regulation of emotional responses in order to avoid the experience and consequences of excessively intense or long emotions (Gross, 2015). However, occasionally regulation goals consist of the desire to up-regulate emotions (Tamir, 2016). For example, bill collectors, bouncers, or police interrogators may at times up-regulate (the expression of) negative emotions in order to fulfill their job requirements (Grandey \& Sayre, 2019). As such, the principles of inertia and regulation typically pull the emotion in different directions and, depending on their relative activity, emotions will strengthen or weaken over time.

The fourth and final principle underlying changes in emotion over time is the principle of interaction. According to this principle, (components of) emotions continuously interact as time progresses, augmenting or blunting each other's activity. At the level of emotion components (e.g., physiological, experiential, and behavioral), these interactions give rise to varying levels of synchronicity or response coherence (Hollenstein \& Lanteigne, 2014). It is notable that synchronicity between emotion components is on average rather low (Mauss \& Robinson, 2009) such that, for example, an increase in the subjective feeling component of anger may co-occur with an increase in heart rate, but definitely not necessarily so. At the level of emotions, the principle of interaction refers to the degree to which changes in activity in one emotion (e.g., anger) are associated with changes in other emotions (e.g., fear) over time. The level of correlation between emotions over time is also considered to reflect to what extent people make coarse- or fine-grained distinctions between emotions, and has been labeled emotion granularity or differentiation (Kashdan, Barrett, \& McKnight, 2015). 


\section{Features of Emotion Dynamics}

Although the principles of emotion dynamics are active "under the hood", they come to surface in a wide range of patterns according to which emotional episodes and affect trajectories unfold over time. These patterns of emotion unfolding have been expressed in a number of dynamic features. In this section, we will provide a brief overview of these features (for a more detailed treatment, see Kuppens \& Verduyn, 2015), separately for dynamics during emotional episodes and within affect trajectories.

\section{Emotional episodes}

Emotional episodes are first of all characterized by a remarkable range of possible durations. Specifically, the amount of time between the start and end of an emotional episode has been shown to vary from only a few seconds up to several hours (for a review, see Van Mechelen et al., 2013). Emotion duration is connected to several principles of emotion dynamics. For example, emotion duration is related to the principle of contingency as the duration of emotional episodes has been shown to be positively related to the presence and importance of the emotion-eliciting event (Verduyn, Delvaux, Van Coillie, Tuerlinckx, \& Van Mechelen, 2009) as well as the degree to which the event matches with one's goals (Verduyn, Van Mechelen, Tuerlinckx, \& Scherer, 2013). Moreover, it has been shown that mood-congruent thoughts are positively associated with emotion duration (principle of inertia), while regulation strategies such as reappraisal or distraction lead to the opposite effect, that is, shorter emotional experiences (principle of regulation) (Verduyn, Van Mechelen, \& Tuerlinckx, 2011).

In addition to duration, emotional episodes also show large variability in the patterns of intensity changes occurring during the episode or so-called intensity profiles (Heylen, Verduyn, Van Mechelen, \& Ceulemans, 2015). Using functional principal component analyses it has been shown that this variability in intensity patterns can be largely described in terms of three dynamic features: explosiveness, accumulation, and reactivation (Verduyn, Van Mechelen, \& Frederix, 2012; Verduyn, Van Mechelen, Tuerlinckx, Meers, \& Van Coillie, 2009). Explosiveness refers to the steepness of the emotional response at onset. Accumulation refers to the degree to which the emotion first intensifies before eventually returning to its baseline level. Reactivation refers to the number of intensity peaks during the emotional episode. Each of these features can be connected to one or more principles of emotion dynamics. For example, whereas each of the three features has been shown to be related to the presence of the emotion-eliciting event (principle of contingency), accumulation was found to be also positively connected to rumination (principle of inertia) (Résibois et al., 2018; Verduyn et al., 2012) and negatively connected to adaptive regulation strategies such as positive reappraisal or perspective taking (principle of regulation) (Heylen et al., 2015).

\section{Affect trajectories}

Four features have been proposed to describe dynamics in affect trajectories: two features at the level of single affect trajectories, and two features at the level of multiple affect trajectories. Regarding single affect trajectories, a first key feature is emotional variability. This feature refers to the degree to which affect trajectory scores portray fluctuations around their mean level and is often calculated as the standard deviation of the trajectory 
scores of an emotion (component) over time (Eid \& Diener, 1999), or the relative standard deviation to avoid floor or ceiling effects (Mestdagh et al., 2018). Emotional variability is connected to the principle of contingency as a high frequency of emotion-provoking events as well as high levels of sensitivity to such events will result in high levels of emotional variability. Both extremely low (Rottenberg, 2005) as well as high (Thompson et al., 2012) levels of emotional variability have been connected to mood disorders.

A second key feature describing patterns of unfolding of single affect trajectories is emotional inertia. This feature reflects the tendency of emotions to carry over from one moment to the next, and is calculated as the autocorrelation of the trajectory scores of an emotion (component) over time (Kuppens, Allen, \& Sheeber, 2010). Inertia is obviously primarily linked to the principle of inertia but also shows a strong connection to the principle of regulation as high inertia scores have been shown to stem from difficulties in emotion regulation (Koval et al., 2015). Unsurprisingly then, high levels of emotional inertia have also been found to be related to mood disorders (e.g., van de Leemput et al., 2014).

Regarding multiple affect trajectories, patterns of emotion unfolding have been described in terms of emotional covariation and emotional cross-lags, with both features being primarily connected to the principle of interaction. Emotional covariation refers to the degree to which changes in emotions (or their components) are aligned, and is typically calculated as the degree of covariation or correlation between the affect trajectories. People experiencing high levels of covariation between different emotions (i.e., low emotional granularity) also experience low levels of well-being (Erbas, Ceulemans, Lee Pe, Koval, \& Kuppens, 2014).

Emotional cross-lags refer to the degree to which activity in a certain emotion (or emotion component) increases (augmenting) or decreases (blunting) activity in another emotion (or emotion component) at a next moment in time, and is typically calculated using time-lagged cross-correlations. Both high levels of augmentation and blunting may indicate that the emotional system is self-contained and cut off from external influences, which is characteristic for mood disorders (Pe et al., 2015).

\section{HOW DYNAMIC COULD ORGANIZATIONAL RESEARCH ON EMOTIONS BE? AN INTEGRATION OF FUNDAMENTAL PRINCIPLES AND FEATURES INTO THE OB LITERATURE}

What can organizational scholars learn from the more fundamental research on emotion dynamics? As has become apparent in this chapter, organizational emotions research has paid very little attention to the temporal character and dynamics of emotional experiences per se. As discussed, this may be due to the general dominance of individual differences as epistemology in organizational research and the lack of specific theory on how emotions arise, operate, and are regulated within individuals and how these dynamics relate to attitudes and behaviors at work (Gooty et al., 2009; Roe, 2008). As has been shown, OB scholars have usually incorporated time in the form of conceptual models, with causes and consequences and the emotional experience as the mechanism in between.

Integrating the principles of emotion dynamics into organizational research may spur a wide variety of innovative research questions: 
Do the patterns of affect trajectories change over the course of one's career?

Does the duration and intensity of emotional episodes change with work experience or organizational tenure?

Do people become more sensitive or more robust to affective events at work (e.g., criticism from customers) when experiencing them on a regular basis?

How do emotional episodes unfold and mutually interact in leader-follower dyads or high-performance teams?

Do the affect trajectories of subordinates follow the pattern of their leaders' trajectory?

Does this happen in parallel or with a certain delay, and what are the consequences for their relationship?

Which types of affective events at work are related to high levels of inertia?

What strategies do employees use to leave "sticky" emotions behind?

Is it possible to create dynamic (i.e., event-based) emotional profiles for different job types, similar to how knowledge, skills, abilities, and other characteristics (KSAOs) are summarized for different jobs in the online database O*NET?

Can we use those dynamic profiles for creating situational judgement tests on affective work events for personnel selection?

How can we integrate our knowledge on the temporal characteristics of emotion dynamics into emotion regulation trainings for service employees?

While this list of questions is not exhaustive, responding to the ones listed here is beyond the scope of this chapter. In the following, we will therefore discuss on the basis of two examples how the principles of emotion dynamics may apply to affect trajectories in the context of AET (Weiss \& Cropanzano, 1996) and to emotional episodes in the context of emotional labor research.

\section{Affective Events and Affect Trajectories}

In an AET framework, emotional experiences have typically been studied in isolation. A promising endeavor for future research would be to look at parallel patterns of emotion unfolding (e.g., with continuous momentary assessment). For example, as research by Rispens and Demerouti (2016) has shown, workplace conflict is associated with a variety of distinct negative emotions. In a first step, the effect of conflict on each of these emotions could be analyzed separately in terms of variability and inertia. It could be tested, for example, if individuals with high levels of variability (i.e., those who react more strongly to conflict) are also more impaired in their performance and show less OCB afterwards. In addition, a similar hypothesis could be tested for those with high levels of inertia (i.e., those who are stuck in their negative emotional states). Negative emotional responses that have become inert and decoupled from events and regulation may result in exhaustion or eventually burnout (De Longis, Alessandri, Sonnentag, \& Kuppens, 2019).

In a second step, drawing on the principle of interaction, scholars could analyze the different emotions' covariation as well as their sequential ordering in terms of cross-lags. Trajectories of guilt and shame might be more strongly related than those of sadness and hostility, and a decrease in anger might lead to an increase in sadness or guilt. Findings of such analyses could, in turn, again be linked to work behavior. For example, while the 
experience of sadness and helplessness followed by anger may mobilize individuals to seek solutions to the conflict (e.g., voice behavior), the reverse sequence may lead to resignation and, over the long run, psychological contract breach. In addition, those types of analyses may also lead to a number of practical implications. Employees who experience very high levels of emotional variability, inertia, and covariation (i.e., low granularity) could receive emotion regulation training in order to attenuate the detrimental consequences for their workplace functioning. For example, research has shown that mindfulness-based interventions are effective in increasing emotion regulation capabilities while reducing stress and anxiety (Eberth \& Sedlmeier, 2012; Hülsheger, Alberts, Feinholdt, \& Lang, 2013).

\section{Emotional Episodes and Emotional Labor}

Building on the work by Gabriel and Diefendorff (2015), who investigated an emotional labor performance episode, future studies could incorporate a more fine-grained analysis of emotional episode features, namely their duration and intensity profiles. As the amount of time between the start and end of an emotional episode can vary remarkably (Van Mechelen et al., 2013) - depending, among other things, on the importance of the emotion-eliciting event (Verduyn et al., 2009) - future studies could try to identify clusters of service interactions with different severity and importance and relate them to different durations and intensity profiles of emotional episodes. For example, customer complaints could be categorized with regard to the hostility of the customer (i.e., the difficulty or unpleasantness of the service interaction) and the importance of customer evaluations for one's performance evaluation and/or salary (i.e., the relevance for one's career). Furthermore, knowing how different emotion regulation strategies (surface acting, deep acting, or automatic regulation; Martínez-Iñigo et al., 2007) are related to the duration of positive or negative emotional experiences may also prove helpful for training employees working in the service industry. For example, future studies could test whether there are instances when surface acting is not so bad after all, for example when service interactions require display of negative emotions (Lennard, Scott, \& Johnson, 2019), are extremely short, or of low personal importance. In addition, emotional labor scholars could investigate the different features of intensity profiles in an emotional labor episode. Specifically, the explosiveness, accumulation, and reactivation of the emotion could predict the type of regulation strategy (Martínez-Iñigo et al., 2007) that people in a service interaction are able to apply. It could be assumed, for instance, that emotional explosiveness (i.e., the steepness of the emotional response at onset) makes antecedentfocused emotion regulation strategies like deep acting more challenging. Research has already evidenced that accumulation, the degree to which the emotion first intensifies before returning to baseline, is negatively related to deep acting strategies such as positive reappraisal or perspective taking (Heylen et al., 2015).

As both examples illustrate, research on emotions in the workplace awaits an exciting future. As pointed out, it is important, however, that OB scholars further invest their efforts in the alignment of emotions theory, measurement, and analysis. Many insights from fundamental emotion dynamic research can help pave that way. At the same time, it is important to mind the importance of investigating emotions in context (Gooty et al., 2009; Weiss, 2002), with work being the most prominent one in most adults' life. As noted by Weiss (2002, p. 1), "people feel guilty at work, they feel angry, they feel happy, they 
feel anxious, often all in the same day. Events at work have real emotional impact . . The consequences of emotional states in the workplace, both behavioral and attitudinal, have substantial significance for individuals, groups, and society."

\section{REFERENCES}

Ashkanasy, N. M. (2003). Emotions in organizations: A multi-level perspective. In F. Dansereau \& F. J. Yammarino (Eds.), Multi-level issues in organizational behavior and strategy (Vol. 2, pp. 9-54). Bingley, UK: Emerald.

Ashkanasy, N. M., \& Humphrey, R. H. (2011). Current emotion research in organizational behavior. Emotion Review, 3(2), 214-224. doi:10.1177/1754073910391684

Ayoko, O. B., Callan, V. J., \& Härtel, C. E. J. (2003). Workplace conflict, bullying, and counterproductive work behaviors. International Journal of Organizational Analysis, 11(4), 283-301. doi:10.1108/eb028976

Barclay, L. J., Skarlicki, D. P., \& Pugh, S. D. (2005). Exploring the role of emotions in injustice perceptions and retaliation. Journal of Applied Psychology, 90(4), 629-643. doi:10.1037/0021-9010.90.4.629

Barrett, L. F. (2014). The conceptual act theory: A précis. Emotion Review, 6(4), 292-297. doi:10.1177/17 54073914534479

Barsade, S. G., Brief, A., \& Spataro, S. (2003). The affective revolution in organizational behavior: The emergence of a paradigm. In J. Greenberg (Ed.), Organizational behavior: The state of the science (pp. 3-52). London: Lawrence Erlbaum Associates.

Barsade, S. G., \& Gibson, D. E. (2007). Why does affect matter in organizations? Academy of Management Perspectives, 21(1), 36-59. doi:10.5465/amp.2007.24286163

Basch, J., \& Fisher, C. D. (2000). Affective events-emotions matrix: A classification of work events and associated emotions. In N. M. Ashkanasy, C. E. J. Härtel, \& W. Zerbe (Eds.), Emotions in the workplace: Research, theory, and practice (pp. 221-235). Westport, CT: Quorum.

Beal, D. J., \& Ghandour, L. (2011). Stability, change, and the stability of change in daily workplace affect. Journal of Organizational Behavior, 32(4), 526-546.

Beal, D. J., Trougakos, J. P., Weiss, H. M., \& Dalal, R. S. (2013). Affect spin and the emotion regulation process at work. Journal of Applied Psychology, 98(4), 593-605. doi:10.1037/a0032559

Bledow, R., Rosing, K., \& Frese, M. (2013). A dynamic perspective on affect and creativity. Academy of Management Journal, 56(2), 432-450. doi:10.5465/amj.2010.0894

Bledow, R., Schmitt, A., Frese, M., \& Kühnel, J. (2011). The affective shift model of work engagement. Journal of Applied Psychology, 96(6), 1246-1257. doi:10.1037/a0024532

Brief, A. P., \& Weiss, H. M. (2002). Organizational behavior: Affect in the workplace. Annual Review of Psychology, 53(1), 279-307. doi:10.1146/annurev.psych.53.100901.135156

Brown, S. P., Westbrook, R. A., \& Challagalla, G. (2005). Good cope, bad cope: Adaptive and maladaptive coping strategies following a critical negative work event. Journal of Applied Psychology, 90(4), $792-798$. doi:10.1037/0021-9010.90.4.792

Chi, N.-W., \& Grandey, A. A. (2019). Emotional labor predicts service performance depending on activation and inhibition regulatory fit. Journal of Management, 45(2), 673-700. doi:10.1177/0149206316672530

Chi, N.-W., Grandey, A. A., Diamond, J. A., \& Royer Krimmel, K. (2011). Want a tip? Service performance as a function of emotion regulation and extraversion. Journal of Applied Psychology, 96(6), 1337-1346. doi:10.1037/a0022884

Davidson, R. J. (1998). Affective style and affective disorders: Perspectives from affective neuroscience. Cognition and Emotion, 12(3), 307-330. doi:10.1080/026999398379628

De Longis, E., Alessandri, G., Sonnentag, S., \& Kuppens, P. (2019). Emotional inertia at work: Correlates of inflexible emotion dynamics in the workplace. Manuscript submitted for publication.

Demerouti, E., \& Cropanzano, R. (2017). The buffering role of sportsmanship on the effects of daily negative events. European Journal of Work and Organizational Psychology, 26(2), 263-274. doi:10.1080/1359 432X.2016.1257610

Diestel, S., Rivkin, W., \& Schmidt, K.-H. (2015). Sleep quality and self-control capacity as protective resources in the daily emotional labor process: Results from two diary studies. Journal of Applied Psychology, 100(3), 809-827. doi:10.1037/a0038373

Eberth, J., \& Sedlmeier, P. (2012). The effects of mindfulness meditation: A meta-analysis. Mindfulness, 3(3), 174-189. doi:10.1007/s12671-012-0101-x

Eid, M., \& Diener, E. (1999). Intraindividual variability in affect: Reliability, validity, and personality correlates. Journal of Personality and Social Psychology, 76(4), 662-676. doi:10.1037/0022-3514.76.4.662 


\section{Handbook on the temporal dynamics of organizational behavior}

Ekman, P. (1984). Expression and the nature of emotion. In K. Scherer \& P. Ekman (Eds.), Approaches to emotion (pp. 319-344). Hillsdale, NJ: Lawrence Erlbaum Associates.

Elfenbein, H. A. (2007). Emotion in organizations. Academy of Management Annals, 1(1), 315-386. doi: $10.1080 / 078559812$

Erbas, Y., Ceulemans, E., Lee Pe, M., Koval, P., \& Kuppens, P. (2014). Negative emotion differentiation: Its personality and well-being correlates and a comparison of different assessment methods. Cognition and Emotion, 28(7), 1196-1213. doi:10.1080/02699931.2013.875890

Fisher, C. D. (2003). Why do lay people believe that satisfaction and performance are correlated? Possible sources of a commonsense theory. Journal of Organizational Behavior, 24(6), 753-777. doi:10.1002/job.219

Frijda, N. H. (1986). The emotions. Cambridge, UK: Cambridge University Press.

Frijda, N. H. (2007). The laws of emotion. Mahwah, NJ: Lawrence Erlbaum Associates.

Frijda, N. H., Mesquita, B., Sonnemans, J., \& Van Goozen, S. (1991). The duration of affective phenomena or emotions, sentiments and passions. In K. T. Strongman (Ed.), International review of studies on emotion (Vol. 1, pp. 187-225). Chichester, UK: Wiley.

Gabriel, A. S., \& Diefendorff, J. M. (2015). Emotional labor dynamics: A momentary approach. Academy of Management Journal, 58(6), 1804-1825. doi:10.5465/amj.2013.1135

Gilboa, E., \& Revelle, W. (1994). Personality and the structure of affective responses. In S. Van Goozen, N. E. Van De Poll, \& J. A. Sargent (Eds.), Essays on current issues in the field of emotion theory (pp. 134-159). Hillsdale, NJ: Erlbaum.

Gooty, J., Gavin, M., \& Ashkanasy, N. M. (2009). Emotions research in OB: The challenges that lie ahead. Journal of Organizational Behavior, 30(6), 833-838.

Grandey, A. A., \& Gabriel, A. S. (2015). Emotional labor at a crossroads: Where do we go from here? Annual Review of Organizational Psychology and Organizational Behavior, 2(1), 323-349. doi:10.1146/annurev-org psych-032414-111400

Grandey, A. A., \& Melloy, R. C. (2017). The state of the heart: Emotional labor as emotion regulation reviewed and revised. Journal of Occupational Health Psychology, 22(3), 407-422. doi:10.1037/ocp0000067

Grandey, A. A., \& Sayre, G. M. (2019). Emotional labor: Regulating emotions for a wage. Current Directions in Psychological Science, 28(2), 131-137. doi:10.1177/0963721418812771

Gross, J. J. (1998). The emerging field of emotion regulation: An integrative review. Review of General Psychology, 2(3), 271-299. doi:10.1037/1089-2680.2.3.271

Gross, J. J. (2015). Emotion regulation: Current status and future prospects. Psychological Inquiry, 26(1), 1-26. doi:10.1080/1047840X.2014.940781

Heylen, J., Verduyn, P., Van Mechelen, I., \& Ceulemans, E. (2015). Variability in anger intensity profiles: Structure and predictive basis. Cognition and Emotion, 29(1), 168-177. doi:10.1080/02699931.2014.896783

Hollenstein, T., \& Lanteigne, D. (2014). Models and methods of emotional concordance. Biological Psychology, 98(1), 1-5. doi:https://doi.org/10.1016/j.biopsycho.2013.12.012

Hülsheger, U. R., \& Schewe, A. F. (2011). On the costs and benefits of emotional labor: A meta-analysis of three decades of research. Journal of Occupational Health Psychology, 16(3), 361-389. doi:10.1037/ a0022876

Hülsheger, U. R., Alberts, H. J. E. M., Feinholdt, A., \& Lang, J. W. B. (2013). Benefits of mindfulness at work: The role of mindfulness in emotion regulation, emotional exhaustion, and job satisfaction. Journal of Applied Psychology, 98(2), 310-325. doi:10.1037/a0031313

Hülsheger, U. R., Lang, J. W. B., Schewe, A. F., \& Zijlstra, F. R. H. (2015). When regulating emotions at work pays off: A diary and an intervention study on emotion regulation and customer tips in service jobs. Journal of Applied Psychology, 100(2), 263-277. doi:10.1037/a0038229

Ilies, R., \& Judge, T. A. (2002). Understanding the dynamic relationships among personality, mood, and job satisfaction: A field experience sampling study. Organizational Behavior and Human Decision Processes, 89(2), 1119-1139. doi:https://doi.org/10.1016/S0749-5978(02)00018-3

Judge, T. A., Woolf Fluegge, E., \& Hurst, C. (2009). Is emotional labor more difficult for some than for others? A multilevel,experience-samplingstudy. PersonnelPsychology,62(1),57-88.doi:10.1111/j.1744-6570.2008.01129.x

Kammeyer-Mueller, J. D., Rubenstein, A. L., Long, D. M., Odio, M. A., Buckman, B. R., Zhang, Y., \& Halvorsen-Ganepola, M. D. K. (2013). A meta-analytic structural model of dispositonal affectivity and emotional labor. Personnel Psychology, 66(1), 47-90. doi:10.1111/peps. 12009

Kashdan, T. B., Barrett, L. F., \& McKnight, P. E. (2015). Unpacking emotion differentiation: Transforming unpleasant experience by perceiving distinctions in negativity. Current Directions in Psychological Science, 24(1), 10-16. doi:10.1177/0963721414550708

Koval, P. (2014). Understanding emotional inertia: Processes underlying the autocorrelation of negative affect (Unpublished doctoral dissertation). University of Leuven, Belgium.

Koval, P., Brose, A., Pe, M. L., Houben, M., Erbas, Y., Champagne, D., \& Kuppens, P. (2015). Emotional inertia and external events: The roles of exposure, reactivity, and recovery. Emotion, 15(5), 625-636. doi:10.1037/ emo0000059 
Kuppens, P., \& Verduyn, P. (2015). Looking at emotion regulation through the window of emotion dynamics. Psychological Inquiry, 26(1), 72-79. doi:10.1080/1047840X.2015.960505

Kuppens, P., \& Verduyn, P. (2017). Emotion dynamics. Current Opinion in Psychology, 17, 22-26. doi:https://doi. org/10.1016/j.copsyc.2017.06.004

Kuppens, P., Allen, N. B., \& Sheeber, L. B. (2010). Emotional inertia and psychological maladjustment. Psychological Science, 21(7), 984-991. doi:10.1177/0956797610372634

Kuppens, P., Van Mechelen, I., Nezlek, J. B., Dossche, D., \& Timmermans, T. (2007). Individual differences in core affect variability and their relationship to personality and psychological adjustment. Emotion, 7(2), 262-274. doi:10.1037/1528-3542.7.2.262

LaBar, K. S., \& Cabeza, R. (2006). Cognitive neuroscience of emotional memory. Nature Reviews Neuroscience, 7(1), 54-64. doi:10.1038/nrn1825

Lennard, A. C., Scott, B. A., \& Johnson, R. E. (2019). Turning frowns (and smiles) upside down: A multilevel examination of surface acting positive and negative emotions on well-being. Journal of Applied Psychology. doi:10.1037/ap10000400

Lerner, J. S., \& Keltner, D. (2001). Fear, anger, and risk. Journal of Personality and Social Psychology, 81(1), 146-159. doi:10.1037/0022-3514.81.1.146

Martínez-Iñigo, D., Totterdell, P., Alcover, C. M., \& Holman, D. (2007). Emotional labour and emotional exhaustion: Interpersonal and intrapersonal mechanisms. Work \& Stress, 21(1), 30-47. doi:10.1080/02678370701234274

Maslach, C., Schaufeli, W. B., \& Leiter, M. P. (2001). Job burnout. Annual Review of Psychology, 52(1), $397-422$. doi:10.1146/annurev.psych.52.1.397

Mauss, I. B., \& Robinson, M. D. (2009). Measures of emotion: A review. Cognition and Emotion, 23(2), $209-237$. doi:10.1080/02699930802204677

Mesmer-Magnus, J. R., DeChurch, L. A., \& Wax, A. (2012). Moving emotional labor beyond surface and deep acting: A discordance-congruence perspective. Organizational Psychology Review, 2(1), 6-53. doi:10.1177/2041386611417746

Mestdagh, M., Pe, M., Pestman, W., Verdonck, S., Kuppens, P., \& Tuerlinckx, F. (2018). Sidelining the mean: The relative variability index as a generic mean-corrected variability measure for bounded variables. Psychological Methods, 23(4), 690-707. doi:10.1037/met0000153

Moors, A. (2014). Flavors of appraisal theories of emotion. Emotion Review, 6(4), $303-307$. doi: $10.1177 / 1754073914534477$

Ouweneel, E., Le Blanc, P. M., Schaufeli, W. B., \& van Wijhe, C. I. (2012). Good morning, good day: A diary study on positive emotions, hope, and work engagement. Human Relations, 65(9), 1129-1154. doi:10.1177/0018 726711429382

Pe, M. L., Kircanski, K., Thompson, R. J., Bringmann, L. F., Tuerlinckx, F., Mestdagh, M., ... Gotlib, I. H. (2015). Emotion-network density in major depressive disorder. Clinical Psychological Science, 3(2), $292-300$. doi:10.1177/2167702614540645

Résibois, M., Kalokerinos, E. K., Verleysen, G., Kuppens, P., Van Mechelen, I., Fossati, P., \& Verduyn, P. (2018). The relation between rumination and temporal features of emotion intensity. Cognition and Emotion, 32(2), 259-274. doi:10.1080/02699931.2017.1298993

Rimé, B. (2009). Emotion elicits the social sharing of emotion: Theory and empirical review. Emotion Review, 1(1), 60-85. doi:10.1177/1754073908097189

Rispens, S., \& Demerouti, E. (2016). Conflict at work, negative emotions, and performance: A diary study. Negotiation and Conflict Management Research, 9(2), 103-119.

Roe, R. A. (2008). Time in applied psychology: The study of "what happens" rather than "what is". European Psychologist, 13(1), 37-52. doi:10.1027/1016-9040.13.1.37

Rothbard, N. P., \& Wilk, S. L. (2011). Waking up on the right or wrong side of the bed: Start-of-workday mood, work events, employee affect, and performance Academy of Management Journal, 54(5), 959-980. doi:10.5465/amj.2007.0056

Rottenberg, J. (2005). Mood and emotion in major depression. Current Directions in Psychological Science, 14(3), 167-170. doi:10.1111/j.0963-7214.2005.00354.x

Scherer, K. R. (2000). Emotions as episodes of subsystem synchronization driven by nonlinear appraisal processes. In M. D. Lewis \& I. Granic (Eds.), Emotion, development, and self-organization: Dynamic systems approaches to emotional development (pp. 70-99). Cambridge, UK: Cambridge University Press.

Scherer, K. R. (2009). The dynamic architecture of emotion: Evidence for the component process model. Cognition and Emotion, 23(7), 1307-1351. doi:10.1080/02699930902928969

Scherer, K. R., \& Wallbott, H. G. (1994). Evidence for universality and cultural variation of differential emotion response patterning. Journal of Personality and Social Psychology, 66(2), 310-328. doi:10.1037/00 22-3514.66.2.310

Schreurs, B., Guenter, H., Hülsheger, U. R., \& van Emmerik, H. (2014). The role of punishment and reward sensitivity in the emotional labor process: A within-person perspective. Journal of Occupational Health Psychology, 19(1), 108-121. doi:10.1037/a0035067 


\section{Handbook on the temporal dynamics of organizational behavior}

Scott, B. A., \& Barnes, C. M. (2011). A multilevel field investigation of emotional labor, affect, work withdrawal, and gender. Academy of Management Journal, 54(1), 116-136. doi:10.5465/AMJ.2011.59215086

Sheldon, K. M., Ryan, R., \& Reis, H. T. (1996). What makes for a good day? Competence and autonomy in the day and in the person. Personality and Social Psychology Bulletin, 22(12), 1270-1279. doi:10.1177/0146167296221 2007

Shockley, K. M., Ispas, D., Rossi, M. E., \& Levine, E. L. (2012). A meta-analytic investigation of the relationship between state affect, discrete emotions, and job performance. Human Performance, 25(5), 377-411. doi:10.1 080/08959285.2012.721832

Tamir, M. (2016). Why do people regulate their emotions? A taxonomy of motives in emotion regulation. Personality and Social Psychology Review, 20(3), 199-222. doi:10.1177/1088868315586325

Thompson, R. J., Mata, J., Jaeggi, S. M., Buschkuehl, M., Jonides, J., \& Gotlib, I. H. (2012). The everyday emotional experience of adults with major depressive disorder: Examining emotional instability, inertia, and reactivity. Journal of Abnormal Psychology, 121(4), 819-829. doi:10.1037/a0027978

Tracy, J. L. (2014). An evolutionary approach to understanding distinct emotions. Emotion Review, 6(4), 308-312. doi:10.1177/1754073914534478

Trougakos, J. P., Beal, D. J., Green, S. G., \& Weiss, H. M. (2008). Making the break count: An episodic examination of recovery activities, emotional experiences, and positive affective displays. Academy of Management Journal, 51(1), 131-146. doi:10.5465/amj.2008.30764063

van de Leemput, I. A., Wichers, M., Cramer, A. O. J., Borsboom, D., Tuerlinckx, F., Kuppens, P., . . Scheffer, M. (2014). Critical slowing down as early warning for the onset and termination of depression. Proceedings of the National Academy of Sciences, 111(1), 87-92. doi:10.1073/pnas.1312114110

Van Mechelen, I., Verduyn, P., \& Brans, K. (2013). The duration of emotional episodes. In D. Hermans, B. Rimé, \& B. Mesquita (Eds.), Changing emotions (pp. 174-180). London: Psychology Press.

Verduyn, P., Delaveau, P., Rotgé, J.-Y., Fossati, P., \& Van Mechelen, I. (2015). Determinants of emotion duration and underlying psychological and neural mechanisms. Emotion Review, 7(4), 330-335. doi:10.1177/1754073915590618

Verduyn, P., Delvaux, E., Van Coillie, H., Tuerlinckx, F., \& Van Mechelen, I. (2009). Predicting the duration of emotional experience: Two experience sampling studies. Emotion, 9(1), 83-91. doi:10.1037/a0014610

Verduyn, P., Van Mechelen, I., \& Frederix, E. (2012). Determinants of the shape of emotion intensity profiles. Cognition and Emotion, 26(8), 1486-1495. doi:10.1080/02699931.2012.662152

Verduyn, P., Van Mechelen, I., \& Tuerlinckx, F. (2011). The relation between event processing and the duration of emotional experience. Emotion, 11(1), 20-28. doi:10.1037/a0021239

Verduyn, P., Van Mechelen, I., Tuerlinckx, F., Meers, K., \& Van Coillie, H. (2009). Intensity profiles of emotional experience over time. Cognition and Emotion, 23(7), 1427-1443. doi:10.1080/02699930902949031

Verduyn, P., Van Mechelen, I., Tuerlinckx, F., \& Scherer, K. (2013). The relation between appraised mismatch and the duration of negative emotions: Evidence for universality. European Journal of Personality, 27(5), 481-494. doi:10.1002/per.1897

Wagner, D. T., Barnes, C. M., \& Scott, B. A. (2014). Driving it home: How workplace emotional labor harms employee home life. Personnel Psychology, 67(2), 487-516. doi:10.1111/peps. 12044

Watson, D., Clark, L. A., \& Tellegen, A. (1988). Development and validation of brief measures of positive and negative affect: The PANAS scales. Journal of Personality and Social Psychology, 54(6), 1063-1070. doi:10.1037/0022-3514.54.6.1063

Weiss, H. M. (2002). Introductory comments: Antecedents of emotional experiences at work. Motivation and Emotion, 26(1), 1-2.

Weiss, H. M., \& Beal, D. J. (2005). Reflections on affective events theory. In N. M. Ashkanasy, W. J. Zerbe, \& C. E. Härtel (Eds.), Research on emotion in organizations (Vol. 1, pp. 1-21). Bingley, UK: Emerald.

Weiss, H. M., \& Cropanzano, R. (1996). Affective events theory: A theoretical discussion of the structure, causes and consequences of affective experiences at work. In B. M. Staw \& L. L. Cummings (Eds.), Research in organizational behavior (Vol. 18, pp. 1-74). Greenwich, CT: JAI Press.

Wichers, M., Wigman, J. T. W., \& Myin-Germeys, I. (2015). Micro-level affect dynamics in psychopathology viewed from complex dynamical system theory. Emotion Review, 7(4), 362-367. doi:10.1177/1754073915590623

Yang, L.-Q., Simon, L. S., Wang, L., \& Zheng, X. (2016). To branch out or stay focused? Affective shifts differentially predict organizational citizenship behavior and task performance. Journal of Applied Psychology, 101(6), 831-845. doi:10.1037/apl0000088

Yiend, J. (2010). The effects of emotion on attention: A review of attentional processing of emotional information. Cognition and Emotion, 24(1), 3-47. doi:10.1080/02699930903205698 